4. Deeb GM, Williams DM, Bolling SF, Quint LE, Monaghan RN, Sievers $\mathrm{J}$, et al. Surgical delay for acute type A dissection with malperfusion. Ann Thorac Surg. 1997;64:1669-75.
5. Kuker W, Weller M, Lose U, Krapf H, Dichgans J, Nagele T. Diffusionweighted MRI of spinal cord infarction-high resolution imaging and time course of diffusion abnormality. J Neurol. 2004;251:818-24.

\title{
New graft formulation and modification of the David reimplantation technique
}

\author{
Thomas G. Gleason, MD, Chicago, III
}

See related editorial on page 243 .

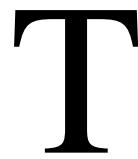

wo controversies of the reimplantation technique ${ }^{1}$ for valve-sparing aortic root replacement are how to choose the graft size and the role of neosinuses. Dating back to the original David-Feindel formula that was based on an assumption that "the internal radius of the ventriculo-aortic junction (the annulus) . . . is two thirds of the leaflet height,"1 surgeons have had difficulty determining optimal graft size. David, in fact, has changed his graft formulation strategy at least 3 times. ${ }^{2}$ Part of the impetus for the modifications in technique was the recognition that recreating aortic sinus segments is important to minimizing stress on the aortic cusps during systole. Data suggest that the techniques currently used still cause undue stress (albeit improved) on the cusps, even with recreation of neosinuses. ${ }^{3}$ The principal hypothesis of this report is that the formulations in use probably underestimate optimal sinus diameter. An alternative and simpler formula with modification of the reimplantation technique is presented.

\section{Methods}

The geometry and relative dimensions of the normal human aortic root were previously characterized, confirming a constant ratio of the dimensions of the sinus diameter, sinotubular junction, commissural heights, and cusp height relative to the annular diameter. ${ }^{4}$ Extrapolating from these data for the purposes of graft size selection and subsequent graft tailoring, 2 important relationships are noted: $h=0.7 d$ and $d^{\prime}=2(0.73 d)$, where $h$ is defined as average cusp height, $d$ is defined as internal annular diameter, and $d^{\prime}$ is

\footnotetext{
From the Division of Cardiothoracic Surgery, Department of Surgery, Northwestern University Feinberg School of Medicine, Chicago, Ill.

Received for publication Feb 1, 2005; accepted for publication Feb 15, 2005.

Address for reprints: Thomas G. Gleason, MD, Northwestern University Feinberg School of Medicine, Galter 10-105, 201 East Huron St, Chicago, IL 60611-3056 (E-mail: tgleason@ nmh.org).

J Thorac Cardiovasc Surg 2005;130:601-3

$0022-5223 / \$ 30.00$

Copyright $\odot 2005$ by The American Association for Thoracic Surgery

doi:10.1016/j.jtcvs.2005.02.016
}

defined as external sinus diameter (Figure 1). At the time of root replacement, the average cusp height is the only relatively fixed measurement, and thus all other diameters can be tailored to accommodate this value. The annulus should be supported (encircled) by graft to recreate $d=h \div 0.7$, and the graft size should be $d^{\prime}=2(0.73 d)$ or $d^{\prime}=2[0.73(h \div 0.7)]$ for that given $h$. This formula for $d^{\prime}$ can then be simplified to $d^{\prime}=2 h+1 \sim 2 \mathrm{~mm}$, where the added 1 to $2 \mathrm{~mm}$ approximates the constant $(0.73 / 0.7)$ for the range of cusp heights typically seen $(13-18 \mathrm{~mm})$, corresponding to a graft size of 28 to $38 \mathrm{~mm}$ (Figure 1).

Graft tailoring and valve reimplantation have also been modified to recreate normal geometric relationships of the root to achieve optimal valve function and reduced cusp stress. The graft is tailored to accommodate the desired annular diameter $(d=$ $h \div 0.7$ ) by using 3 pleats that are positioned at the nadir of each sinus (midcusp). Each pleat is positioned at the level of the hinge point at midcusp to allow for maximum billowing of the graft above and creation of neosinuses. A triangular groove is cut in the graft to accommodate the attachment of the left-right commissure to ventricular muscle, and the neosinotubular junction is fashioned after reimplantation with pleats at the same corresponding (ie, midsinus) sites (Figure 1).

The annulus is dissected out circumferentially, including some of its fibrous continuity. The valve is reimplanted with 2 suture lines: the first is a subcusp-annular suture line placed with horizontal mattress sutures in a coronet-shaped, 3-dimensional annular fashion, and the second is a running suture line placed supra-annularly, incorporating residual aorta, annulus, and graft (Figure 2). The graft circumferentially supports the annulus, the fibrous continuity of the ventriculoaortic junction, and the commissures.

This graft formulation and modified reimplantation technique has been used in 9 patients (aged 15-66 years) with a variety of aneurysm abnormalities, including Marfan syndrome, bicuspid aortic valve, and acute aortic dissection. There have been no deaths, strokes, reoperations, or episodes of heart block. Patients are being followed up with echocardiography and computed tomographic angiography. One patient (with bicuspid aortic valve) has mild $(1+)$ aortic regurgitation (AR) at 1 year, but to date, none of the other patients have any aortic insufficiency.

\section{Discussion}

Conceptually, the reimplantation technique is an attractive operation because the native valve is spared and subsequent annular dilatation is completely prevented by circumferential graft support. 

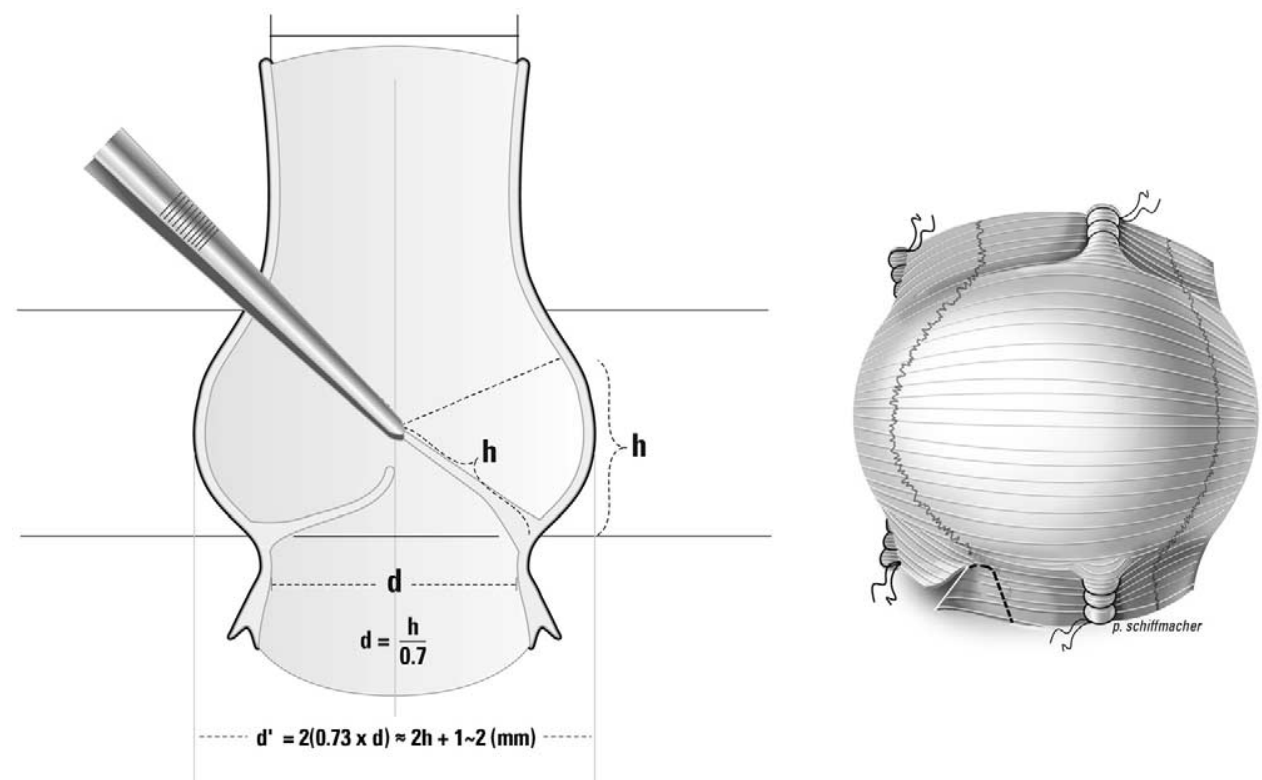

Figure 1. Normal human aortic root dimensions relative to cusp height for the internal annular diameter and the external sinus diameter are depicted on the left. A tailored aortic root graft is depicted on the right.

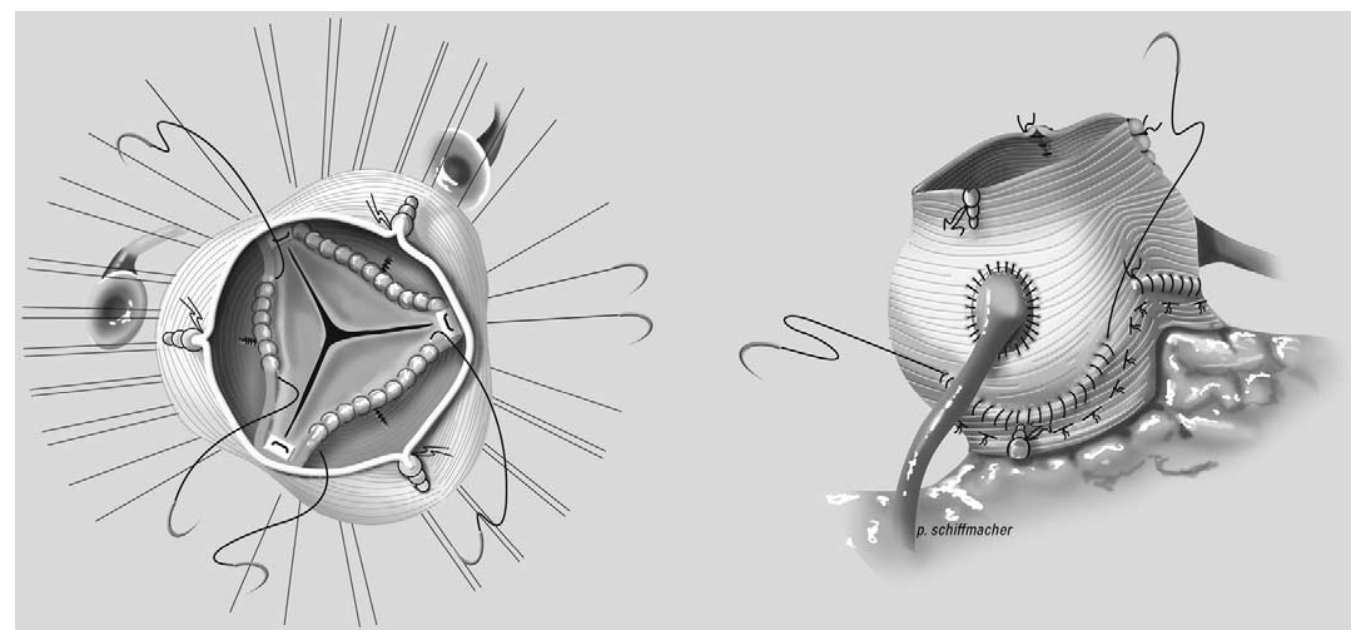

Figure 2. Reimplantation of the aortic valve in the tailored aortic root graft with neosinus creation is depicted from the superior and anterior anatomic views, respectively.

The primary limitations are its technical demand and the potential for progressive aortic insufficiency caused by cusp stress, leading to cusp injury, fibrosis, or prolapse. In the largest reported series, the 5-year reoperation rate was $3.2 \%$, but $6 \%$ had 3-4+ AR, and $32 \%$ had $1+\mathrm{AR}$ at last follow-up. ${ }^{5}$ Creation of neosinuses by previously reported techniques has not eliminated cusp stress, and this, in part, might be due to the fact that the sinuses created were not large enough to restore normal geometric relationships to optimize laminar flow through the valve. ${ }^{3,4}$ This new graft formula presented is simple, predicts a larger graft size than previously reported, and is based on normal root dimensions. It will require continued analysis to prove that cusp stress has been adequately reduced. Dynamic imaging studies are currently underway to identify a better means of evaluating flow patterns and cusp stress.

\section{References}

1. David TE, Feindel CM. An aortic valve-sparing operation for patients with aortic incompetence and aneurysm of the ascending aorta. $J$ Thorac Cardiovasc Surg. 1992;103:617-22. 
2. Miller DC. Valve-sparing aortic root replacement in patients with the Marfan syndrome. J Thorac Cardiovasc Surg. 2003;125:773-8.

3. Grande-Allen KJ, Cochran RP, Reinhall PG, Kunzelman KS. Re-creation of sinuses is important for sparing the aortic valve: a finite element study. J Thorac Cardiovasc Surg. 2000;119:753-63.
4. Swanson M, Clark RE. Dimensions and geometric relationships of the human aortic valve as a function of pressure. Circ Res. 1974;35:871-82.

5. Kallenbach K, Hagl C, Walles T, Leyh RG, Pethig K, Haverich A, et al. Results of valve-sparing aortic root reconstruction in 158 consecutive patients. Ann Thorac Surg. 2002;74:2026-33.

\section{Percutaneous repair of an ascending aortic pseudoaneurysm with a septal occluder device}

Christopher B. Komanapalli, MD, ${ }^{a}$ Grant Burch, MD, ${ }^{b}$ Uttam Tripathy, MD, Matthew S. Slater, MD, and Howard K. Song, MD, ${ }^{a}$ Portland, Ore

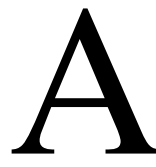

scending aortic ${ }^{1}$ pseudoaneurysms are rare complications of cardiovascular surgery. ${ }^{1}$ Repair of ascending aortic pseudoaneurysms in the past has required redo sternotomy and cardiopulmonary bypass for suture or patch repair. For patients who are poor surgical candidates, catheter-based interventions have been considered to repair this potentially lethal complication. Two cases of ascending aortic pseudoaneurysm have been previously reported in which catheter-based therapy was used., ${ }^{2,3}$ One described placement of a Fogarty balloon catheter to provide temporary occlusion of a pseudoaneurysm before surgical intervention. ${ }^{2}$ The other involved catheter-based delivery of thrombin into the pseudoaneurysm that resulted in thrombus propagation into the ascending aorta, leading to transient ischemic attack. ${ }^{3}$ Here we present the successful use of an Amplatzer septal occluder (AGA Medical Corp, Golden Valley, Minn) to exclude a pseudoaneurysm from the ascending aorta of a patient who was a poor candidate for operative intervention (Figure 1).

\section{Clinical Summary}

A 79-year-old woman underwent elective aortic valve replacement with a bioprosthetic valve at another institution. Her medical history was significant for aortic stenosis, atrial fibrillation, and congestive heart failure. Her postoperative course was complicated by postoperative hemorrhage requiring re-exploration, as well as prolonged intensive care unit stay because of respiratory and renal

\footnotetext{
From the Department of Surgery, Division of Cardiothoracic Surgery, a and the Department of Pediatrics, Division of Cardiology, ${ }^{\mathrm{b}}$ Oregon Health and Science University, Portland, Ore.

Received for publication Feb 10, 2005; accepted for publication Feb 24, 2005.

Address for reprints: Howard K. Song, MD, OHSU Division of Cardiothoracic Surgery, Mail Code: L353, 3181 SW Sam Jackson Park Rd, Portland, OR 97239 (E-mail: songh@ohsu.edu).

J Thorac Cardiovasc Surg 2005;130:603-4

$0022-5223 / \$ 30.00$

Copyright $\odot 2005$ by The American Association for Thoracic Surgery doi:10.1016/j.jtcvs.2005.02.044
}

failure. Five months after aortic valve replacement, the patient presented with shortness of breath and hemoptysis. A computed tomographic scan demonstrated a large pseudoaneurysm originating from

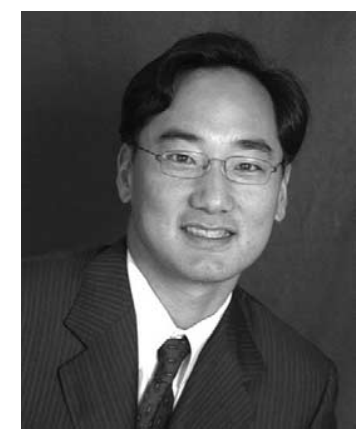

Dr Song the mid-ascending aorta measuring $3.8 \times 6.5 \mathrm{~cm}$ (Figure 2, A). Laboratory studies revealed normal white blood cell counts, and blood cultures obtained on admission were negative. Transesophageal echocardiography confirmed the presence of the lesion and demonstrated blood flow into the sac through a narrow communication with the ascending aorta. A long discussion was held with the patient and her family regarding the risks and benefits of traditional operative repair given the patient's age, heart failure,

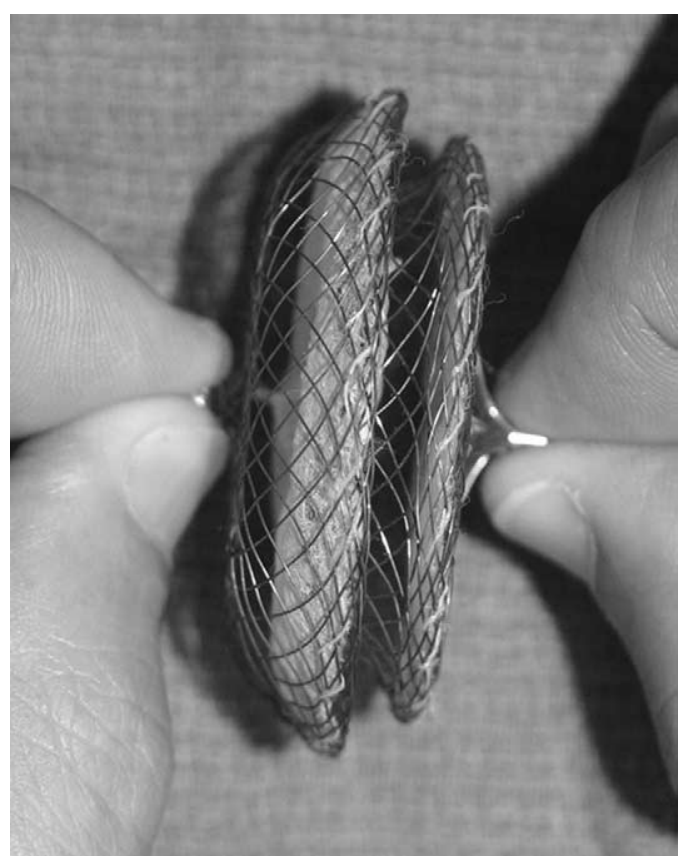

Figure 1. Photograph of the Amplatzer septal occluder in its deployed shape. 